\title{
Hubungan Tingkat Pengetahuan tentang Perubahan Fisiologis dan Psikologis Fase Premenopouse terhadap Tingkat Kecemasan pada Pralansia
}

\author{
Relationships of Knowledge Level about Physiological and Psychological \\ Changes in premenopausal phase towards Anxiety Levels on Pre-old women
}

\author{
Zulina, Ennimay, Yecy Anggreny
}

\section{Program Studi Ilmu Keperawatan STIKes Hang Tuah Pekanbaru}

\begin{abstract}
ABSTRAK
Pengetahuan merupakan hasil dari penginderaan manusia yang sangat dipengaruhi oleh intensitas perhatian dan persepsi terhadap objek. Kecemasan merupakan perasaan takut yang tidak jelas dan tidak didukung oleh situasi. Penelitian ini bertujuan untuk mengetahui hubungan tingkat pengetahuan tentang perubahan fisiologis dan psikologis fase premenopouse terhadap tingkat kecemasan pada pralansia. Penelitian ini merupakan penelitian kuantitatif dengan desain "cross sectional". Sampel dalam penelitian ini bejumlah 90 orang wanita pralansia yang mengalami premenopouse di Wilayah Kerja Puskesmas Lima Puluh Pekanbaru, diambil menggunakan teknik purposive sampling. Analisis data dilakukan secara univariat dengan distribusi frekuensi dan bivariat dengan uji chi-square. Hasil penelitian menunjukkan terdapat hubungan antara tingkat pengetahuan tentang perubahan fisiologis dan psikologis fase premenopouse terhadap tingkat kecemasan pada pralansia dengan $p$ value $=0,000(\mathrm{p}<0,1)$. Penelitian ini menyarankan agar dilakukan penelitian dengan variabel lain seperti dukungan keluarga, ekonomi dan pendidikan.
\end{abstract}

Kata kunci : wanita pralansia, pengetahuan, kecemasan.

\section{ABSTRACT}

Knowledge was the resulted of human sensing that strongly influenced by the intensity of attention and object perception. Anxiety was a felt of fear that was not clear and not supported by the situation. This study aims to determine the relationship betwen level of knowledge about physiological and psychological changes in premenopausal phase and level of anxiety in pre-old woman. This research was quantitative design with cross-sectional. Total sample in this study are 90 premenopausal women who experience pre-old women at Working Area of Health Public Center in Pekanbaru, used purposive sampling technique. Data was analyzed with univariate and bivariate frequency distributions with chi-square test. The results showed an relationship between the level of knowledge about the physiological and psychological changes in premenopausal phase and the level of anxiety in pre-old women with $p$ value $=0.000(p<0.1)$. This study recommended that additional studies by increasing the number of samples so that the whole population can be represented.

Keywords : pre-old women, knowledge, anxiety.

\section{PENDAHULUAN}

Lanjut usia adalah bagian dari proses tumbuh kembang. Manusia tidak secara tiba-tiba menjadi tua, tetapi berkembang dari bayi, anak-anak, dewasa dan akhirnya menua. Tahap menua dimulai dari pralansia, lansia, lansia tua hingga lansia sangat tua (Azizah, 2011).

Pada tahap pralansia terdapat beberapa tanda yang merupakan awal dari proses penuaan, terutama pada wanita, proses menua pada wanita ditandai dengan terjadinya suatu fase yaitu fase menopouse Proverawati (2011). Sebelum terjadi fase menopouse, wanita akan mengalami fase premenopouse. Mengalami premenopouse atau yang disebut dengan masa 4-5 tahun sebelum menopouse adalah suatu karunia, karena keadaan ini merupakan proses penuaan yang sangat alamiah dan normal pada setiap wanita.
Premenopouse bukanlah masalah medis dan bukan suatu penyakit ataupun kelainan. Premenopouse adalah fase yang ditandai dengan siklus haid yang tidak teratur, dengan pendarahan haid yang relatif banyak, dan kadang-kadang disertai nyeri haid (dismenorea) (Baziad, 2003).

Proses premenopouse juga banyak menimbulkan perubahan psikologis yang sifatnya sangat individual dan dipengaruhi oleh sosial budaya, pendidikan, lingkungan, dan ekonomi. Keluhan fisik maupun psikis seperti penurunan daya ingat, mudah tersinggung dan depresi (rasa cemas) tentu akan mengganggu kesehatan wanita yang bersangkutan termasuk perkembangan psikisnya, selain itu juga bisa mempengaruhi kualitas hidupnya. Dalam menyikapi dirinya yang akan memasuki masa premenopouse, 
beberapa wanita menyambutnya dengan biasa, mereka menganggap kondisi ini sebagai bagian dari siklus hidupnya, sedangkan sisanya banyak yang mengeluh bahwa dengan datangnya premenopouse mereka akan menjadi cemas (Proverawati, 2010).

Kecemasan yang dialami oleh wanita dipengaruhi oleh pengetahuan perempuan tentang premenopouse, hal ini sangat penting karena dapat menumbuhkan efek positif pada penataan kondisi psikologis. Kesiapan mental dan pengetahuan yang cukup akan memudahkan seseorang dalam mengontrol depresi, kecemasan, serta gangguan emosional (Setiono, 2004).

Penelitian ini untuk mengetahui hubungan antara tingkat pengetahuan tentang perubahan fisiologis dan psikologis fase premenopouse terhadap tingkat kecemasan pada pralansia

\section{METODE}

Penelitian ini merupakan penelitian kuantitatif dengan desain penelitian cross sectional. Populasi dari penelitian ini adalah semua wanita yang berusia 45-59 tahun yang sedang mengalami premenopouse pada tahun 2013 di Wilayah kerja Puskesmas Lima Puluh Pekanbaru sebanyak 936 pralansia. Lokasi penelitian ini dipilih karena jumlah pralansia di Pekanbaru yang paling banyak dibina adalah di Wilayah kerja Puskesmas Lima Puluh Pekanbaru. Besar sampel yang diperoleh dengan tingkat signifikasi $10 \%$ adalah 90 responden. Proses pengambilan sampel dalam penelitian ini menggunakan teknik purposive sampling, yaitu cara pengambilan sampel dengan kriteria-kriteria tertentu yang ditetapkan oleh peneliti.

Variabel dalam penelitian ini terdiri atas variabel independen dan dependen. Variabel independen adalah tingkat pengetahuan dan dependen adalah tingkat kecemasan. Data pada penelitian ini dikumpulkan melalui wawancara, observasi langsung dan kuesioner yang telah dilakukan uji validitas. Analisis dilakukan menggunakan uji Chi Square untuk melihat apakah ada hubungan antara variabel independen dan dependen.

\section{HASIL}

\section{Analisis Univariat}

Analisis univariat dilakukan terhadap setiap variabel yang diukur dalam penelitian ini menggunakan distribusi frekuensi. Penelitian ini mendapatkan bahwa tingkat pendidikan responden mayoritas adalah SMA yaitu sebanyak 35 responden (38,9\%), sedangkan umur responden mayoritas berada pada rentang 45-50 tahun yaitu sebanyak $71(78,9 \%)$ responden, untuk kategori usia 56-59 tahun hanya satu responden. Tingkat pengetahuan responden mayoritas berpengetahuan rendah yaitu 48 responden $(53,3 \%)$, sedangkan tingkat kecemasan responden mayoritas mengalami kecemasan yaitu 58 (64,4\%) responden, sedangkan yang tidak mengalami kecemasan hanya 32 responden $(35,6 \%)$.

\section{Analisis Bivariat}

Analisis bivariat dilakukan untuk melihat hubungan antara variabel independen (tingkat pengetahuan) dan dependen (tingkat kecemasan) pada pralansia wanita yang sedang mengalami premenopouse. Uji statistik pada penelitian ini menggunakan uji Chi Square untuk mengetahui apakah ada hubungan antara tingkat pengetahuan tentang perubahan fisiologis dan psikologis tubuh fase premenopouse terhadap tingkat kecemasan pada pralansia. Hubungan antara variabel independen dan dependen dalam penelitian ini dapat dilihat pada tabel berikut.

Tabel.1

Hubungan Tingkat Pengetahuan dengan Tingkat Kecemasan Wanita Pralansia di Wilayah Kerja Puskesmas Lima Puluh Pekanbaru Tahun 2013

\begin{tabular}{|c|c|c|c|c|c|c|c|c|c|}
\hline \multirow{3}{*}{$\begin{array}{l}\text { Tingkat } \\
\text { Pengeta } \\
\text { huan }\end{array}$} & \multicolumn{6}{|c|}{ Tingkat Kecemasan } & \multirow{2}{*}{\multicolumn{2}{|c|}{ Total }} & \multirow{3}{*}{$\begin{array}{c}p- \\
\text { valu } \\
e\end{array}$} \\
\hline & \multicolumn{2}{|c|}{$\begin{array}{c}\text { Tidak } \\
\text { Cemas }\end{array}$} & \multicolumn{2}{|c|}{ Ringan } & \multicolumn{2}{|c|}{ Sedang } & & & \\
\hline & $\mathbf{N}$ & $\%$ & $\mathbf{N}$ & $\%$ & $\mathbf{N}$ & $\%$ & $\mathbf{N}$ & $\%$ & \\
\hline Tinggi & 27 & 64,3 & 13 & 31 & 2 & 4,8 & 42 & 100 & \\
\hline Rendah & 5 & 10,4 & 15 & 31,3 & 28 & 58,3 & 48 & 100 & 0,000 \\
\hline Total & 32 & 35,6 & 28 & 31,1 & 30 & 33,3 & 90 & 100 & \\
\hline
\end{tabular}

Berdasarkan Tabel di atas, menunjukkan dilihat bahwa responden yang memiliki pengetahuan tinggi sebanyak 27 orang (30\%) yang tidak mengalami kecemasan, sementara hanya 2 orang $(2,2 \%)$ yang mengalami kecemasan sedang. Responden yang berpengetahuan rendah yang mengalami kecemasan sedang sebanyak 28 orang, dan hanya 5 orang yang tidak mengalami kecemasan.

Hasil uji statistik dengan menggunakan uji Chi-square, diperoleh nilai $p$-value $=0,000,(p<\alpha$ $0,1)$, artinya , sehingga terdapat hubungan yang bermakna antara tingkat pengetahuan tentang perubahan fisiologis dan psikologis fase premenopouse dengan tingkat kecemasan wanita pralansia di Wilayah Kerja Puskesmas Lima Puluh Pekanbaru.

\section{PEMBAHASAN}

Berdasarkan hasil penelitian yang didapatkan, kecemasan wanita pralansia di Wilayah Kerja Puskesmas Lima Puluh Pekanbaru masih dikategorikan tinggi, karena lebih dari 50\% responden mengalami kecemasan ringan dan sedang. Kecemasan pada pralansia wanita ini harus segera ditanggulangi 
karena kecemasan dapat berakibat buruk bagi fisik maupun psikologis wanita pralansia tersebut.

Total pralansia wanita dengan tingkat pengetahuan tinggi sebanyak 42 orang $(46,7 \%)$ dengan 27 responden $(64,3 \%)$ tidak mengalami kecemasan, 13 responden $(31 \%)$ mengalami kecemasan ringan dan 2 responden $(4,8 \%)$ mengalami kecemasan sedang. Untuk responden dengan pengetahuan rendah, 5 responden $(10,4 \%)$ yang tidak mengalami kecemasan, 15 responden $(31,3 \%)$ yang mengalami kecemasan ringan dan 28 responden $(58,3 \%)$ yang mengalami kecemasan sedang. Hasil uji statistik dengan chisquare diperoleh nilai $p$-value $(0,000)$ yang berarti $\mathrm{p}<$ $\alpha(0,1)$, artinya terdapat hubungan yang bermakna antara tingkat pengetahuan tentang perubahan fisiologis dan psikologis fase premenopouse terhadap tingkat kecemasan pada pralansia di Wilayah Kerja Puskesmas Lima Puluh Pekanbaru, artinya semakin tinggi tingkat pengetahuan maka semakin rendah kecenderungan untuk mengalami kecemasan dan semakin rendah tingkat pengetahuan maka semakin tinggi kecenderungan untuk mengalami kecemasan.

Wanita pralansia yang sedang mengalami premenopouse, seperti hot flush, mengkerutnya serviks, ovarium, mengecilnya uterus dan tuba falopi akan rentan mengalami kecemasan jika pengetahuannya kurang tentang peruabahan tersebut. Hal ini sesuai dengan penelitian Aprilia (2007) yang berjudul faktor yang mempengaruhi tingkat kecemasan pada wanita perimenopause, didapati bahwa kecemasan berat banyak dijumpai pada responden yang memiliki tingkat pengetahuan kurang dan cukup dan terdapat hubungan yang bermakna antara tingkat pengetahuan dengan tingkat kecemasan yang berarti semakin kurang tingkat pengetahuan maka semakin tinggi resiko untuk mengalami kecemasan. Hal ini juga sesuai dengan hasil penelitian Indriani (2012), yang menyatakan bahwa terdapat hubungan antara tingkat pengetahuan wanita usia 45-59 tahun tentang menopouse dengan sikap menghadapi gejala menopouse, peneliti menyatakan bahwa responden yang berpengetahuan tinggi tentang menopouse berpeluang 4 kali memiliki sikap positif dalam menghadapi gejala menopouse.

Berdasarkan hasil penelitian terlihat bahwa tingkat pengetahuan tentang perubahan fisiologis dan psikologis fase premenopouse berhubungan dengan tingkat kecemasan, dimana wanita pralansia yang memiliki pengetahuan rendah akan cenderung mengalami kecemasan dalam menghadapi premenopouse. Kecemasan pada wanita premenopouse ini dapat ditanggulangi dengan meningkatkan pengetahuan, agar wanita tersebut menerima perubahan tubuh yang terjadi dan memahami keadaan fisiknya.

\section{KESIMPULAN}

Distribusi frekuensi tingkat kecemasan terhadap perubahan fisiologis dan psikologis fase premenopouse pada pralansia wanita di Wilayah Kerja Puskesmas Lima Puluh Pekanbaru mayoritas mengalami kecemasan yaitu 28 orang $(31,1 \%)$ mengalami kecemasan ringan dan 30 orang $(33,3 \%)$ mengalami kecemasan sedang. Ada hubungan antara tingkat pengetahuan tentang perubahan fisiologis dan psikologis fase premenopouse dengan tingkat kecemasan pada pralansia di Wilayah Kerja Puskesmas Lima Puluh Pekanbaru tahun 2013 dengan p-value 0,000 .

\section{SARAN}

1. Bagi Puskesmas

Diharapkan dengan adanya penelitian ini dapat memberikan informasi kepada pemberi pelayanan kesehatan tentang status kecemasan pralansia yang memiliki pengetahuan kurang tentang menopouse dan pelayanan kesehatan dapat memberikan edukasi kepada masyarakat yang akan mengalami premenopouse agar kecemasan tidak terjadi.

2. Bagi Masyarakat

$\begin{array}{lr}\text { Diharapakan } & \text { masyarakat dapat } \\ \text { meningkatkan } & \text { pengetahuan }\end{array}$ premenopouse, melakukan konsultasi dengan anggota keluarga atau teman yang merupakan tenaga kesehatan atau langsung ke pelayanan kesehatan terdekat untuk mendapatkan informasi yang benar tentang premenopouse dan bagaimana cara menyikapinya agar kecemasan tidak terjadi.

3. Bagi keluarga

Diharapkan keluarga dapat memberikan dukungan, motivasi dengan sering berkomunikasi kepada wanita yang sedang mengalami premenopouse agar wanita tersebut merasa memiliki dorongan untuk meningkatkan kualitas hidupnya dan mengabaikan rasa cemas yang dialaminya.

\section{UCAPAN TERIMA KASIH}

Ucapan terima kasih diberikan kepada Kepala Puskesmas Lima Puluh Pekanbaru yang telah memberikan izin penelitian diwilayah kerjanya dan juga memberikan informasi kepada peneliti.

\section{KEPUSTAKAAN}

Aprilia, N. I. (2007). Faktor yang mempengaruhi tingkat kecemasan pada wanita perimenopouse.

Journal.lib.unair.ac.id/index.php/IJPH/article/ view/470/471. Diakses 23 November 2012. 
Asmadi. (2008). Teknik prosedural keperawatan konsep dan aplikasi kebutuhan dasar klien. Jakarta: Salemba Medika.

Azizah, L. M. (2011). Keperawatan lanjut usia. Yogyakarta: Graha Ilmu.

Indriani. (2012). Hubungan pengetahuan wanita usia 45-59 tahun tentang menopouse dengan sikap menghadapi gejala menopouse di wilayah kerja puskesmas Garuda Pekanbaru tahun 2012. Skripsi tidak dipublikasikan.

Notoadmodjo, S. (2005). Metodologi penelitian kesehatan. Jakarta: Rineka Cipta.

Rostiana, T. (2009). Kecemasan pada wanita yang menghadapi menopouse. http://ejournal.gunadarma.ac.id/index.php/psik o/article/view/407/347. Diakses 22 April 2013 